\title{
The gerontechnology engineer
}

\author{
J.E.M.H. van Bronswijk PhD \\ E: j.e.m.h.v.bronswijk@tue.nl
}

M. Brink MSc

E:m.brink@tue.nl

R.D. van der Vlies MSc PDEng

E: r.d.v.d.vlies@tue.nl

Group Performance Engineering for Built Environment,

Department of the Built Environment,

Eindhoven University of Technology, Eindhoven, The Netherlands

\begin{abstract}
J.E.M.H. van Bronswijk, M. Brink, R.D. van der Vlies. The gerontechnology engineer. Gerontechnology 2011; 10(3):125-128; doi:10.4017/gt.2011.10.3.011.00 Pushing supportive technology to serve an aging society originated from the social sciences. Only about 20 years ago did engineers discover the field and formulated it as gerontechnology. The question arises whether engineers and social scientists have succeeded to form a community of practice with balanced contributions from both sides. Method Google Scholar entries were analyzed with Publish or Perish software, and further categorized manually according to gerontechnology matrices. Results A technology or engineering focus is present in about $1 / 3$ of gerontechnology publications. Two publication channels are dominant: the International Society for Gerontechnology (ISG) and the Institute of Electrical and Electronics Engineers (IEEE), and concern mainly ICT followed by ergonomics \& design, and mechatronics \& robotics. Gerontechnology engineers and technologists authors are largely missing in the disciplines of architecture and construction, business administration and material sciences.
\end{abstract}

\section{Keywords: technology, gerontology, community of practice, interdisciplinary}

In the seventies of the $20^{\text {th }}$ century social scientists founded the Human Factors and Ergonomics Society Technical Group on Aging of which James L. Fozard held the first chair'. 'Technology and Aging' became a widely researched area in North America with social scientists to take the lead ${ }^{2}$. In Europe one of the oldest social science journals on aging 'Gerontology' (established 1957), opened a section 'Technological Gerontology' only a few years ago.

The notion 'gerontechnology', a contraction of gerontology and technology, has been introduced by engineers to incorporate knowledge of social sciences and humanities in the design of new products and services for aging people. Originally the aim of gerontechnology was stated as making technology instrumental in solving problems of the elderly,4; later to be widened to serving the aging society with preventive and supportive interventions in the different application domains or domains of life ${ }^{5}$.

Currently gerontechnology has become wellknown. World conferences of gerontechnology have increased in frequency: $1991^{4}, 1996^{6}$, $1999^{7}, 2002^{8}, 2005^{9}, 2008^{10}$ and $2010^{11}$, with the 2012 conference in full preparation ${ }^{12}$, and the next one already planned for Taipei (Taiwan) in the year $2014^{13}$. Using Gerontechnology as a keyword resulted in 75,200 hits in a general Google search (December 2011) ${ }^{14}$.

However, does the gerontechnology engineer exist, i.e. did a community of practice arise in which social scientists and gerontechnology engineers contributions balance in the different engineering fields? 


\section{Gerontechnology e n gine e r}

\section{Methodology}

Google Scholar, the academic version of Google, was chosen as the main source of raw data, since this literature database is best suited for engineering and the social sciences ${ }^{15}$. Raw data were collected on October 14, 2010. The following keywords from Germanic and Romanic languages were used in a general citation search with Publish-or-Perish software $(\mathrm{PoP})^{16}$ : gerotechnology, gerontechnology, gerontotechnology, gerotechnologie, gerontechnologie, gerontotechnologie, gerotecnologia, gerontecnologia and gerontotecnologia.

Since our search led to more than 1000 academic hits (the maximum of PoP), it has been repeated for each domain recognized by Google Scholar and PoP: (i) Biology, life sciences (including physiology), environmental sciences (5 hits); (ii) Business, Administration, Finance, Economics (166 hits); (iii) Chemistry and Materials Science (13 hits); (iv) Engineering, Computer Science, Mathematics (333 hits); (v) Medicine, pharmacology, veterinary science (147 hits); (vi) Physics, astronomy, planetary science (3 hits); and (vii) Social Sciences, Arts, Humanities (1099 hits in 2 runs, first with the English key words, then with the others). Results were transferred to Excel. Entries consisting of job advertisements or conference programs were removed, and double entries have been combined. In case the information provided was not sufficient for detailed analysis, the reference was completed using the source given by Google Scholar.

The first step in analysis consisted of automatically condensing the classification of the publications in 2 broad academic categories as recognized in gerontechnology ${ }^{2}$ : engineering and technology (groupings ii, iii, iv, vi as mentioned above) and gerontology (items i, v, vii as stated above).

In the second analysis step, the authors independently classified the remaining 1524 periodical publications, proceedings, books and academic theses by (i) application or life domain, and (ii) academic discipline as

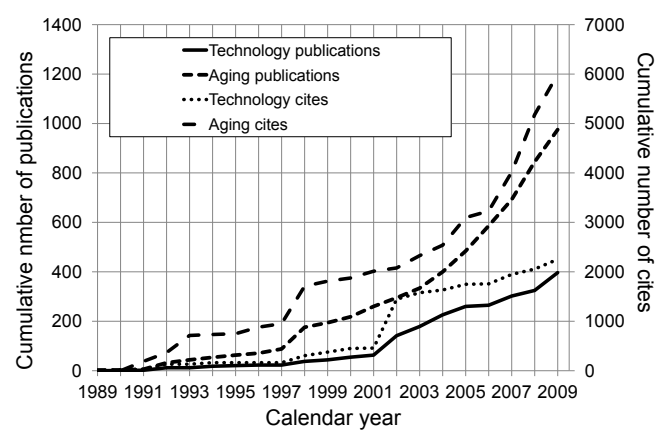

Figure 1. Books, proceedings, academic theses, and journal contributions to gerontechnology in two categories as distributed over the years, and the frequency of their citation up to October 2010

recognized in gerontechnology $y^{5}$. In the first round a classification was accepted when at least 2 of the 3 votes agreed. The remaining articles were re-evaluated in a second round by all 3 authors independently. Forty discrepancies remained and were decided by the first author.

Finally, in the third step, we counted the number of publications, number of cited publications and number of cites of both journal contributions and conference publications.

\section{Results}

After 1991 a gradual growth in frequency started of gerontechnology publications focusing on gerontology, followed after 1997 by an increase in contributions from the engineering and technology side. Only after the $4^{\text {th }}$ World Conference in 2002 did the citing frequency of technology publications improve somewhat. Overall about $1 / 3$ of gerontechnology publications have an engineering or technology focus (Figure 1). The influence of the proceedings and abstracts of the first three world conferences of Gerontechnology is visible (1992, 1998, and 2002). The last full year investigated (2009) had 202 new publications that had been cited 2011 times by October 2010.

\section{Disciplines}

Among the technology en engineering disciplines, most gerontechnology activity is seen in ICT, followed by Ergonomics \& 


\section{Gerontechnology e n gine er}

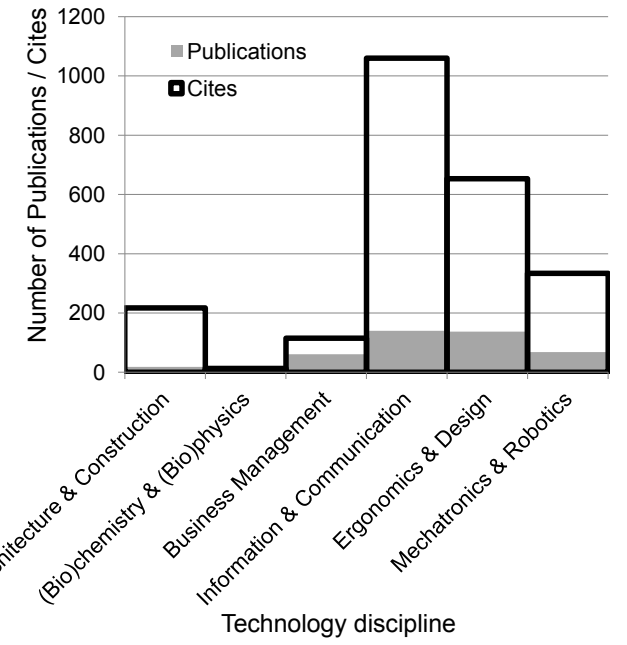

Figure 2. Publications and cites of gerontechnology contributions that focused on specific disciplines of technology and engineering up to October 2010

Design, and Mechatronics \& Robotics. The small number of publications in the domain of Architecture \& Construction is highly cited. Business management is a backwater in gerontechnology, while (bio)chemistry and (bio)physics, such as material science, is virtually nonexistent (Figure 2).

\section{Life domains}

Health and housing are the main life domains of interest in current gerontechnology, with each about $30 \%$ of the total number of publications. Work or leisure produced the lowest number, a meager $6 \%$. Of the 7 publications that were cited more than 100 times,
Surprisingly, the engineering disciplines Architecture \& Construction did not focus on life domains they are usually associated with. Their gerontechnology production in Housing \& Daily living and in Mobility \& Transport is only $0.6-1.5 \%$ of publications in these two life domains respectively.

\section{Publication channels}

Both journals and conference books are publication channels for gerontechnology. Only two organizations have a considerably impact in both domains: ISG (International Society for Gerontechnology) and IEEE (Institute of Electrical and Electronics Engineers). These organizations have been established by engineers, but their main focus in gerontechnology publications appears to be on the aging sciences, rather than on technology or engineering (Table 1).

\section{Discussion}

Sharing of information, methods and experiences is essential for the collaboration between engineers and technologists on one side and gerontologists on the other. The three conditions of a successful, but informal 'community of practice' seem to be fulfilled $^{17}$ : (i) a common domain of interest (gerontechnology), (ii) a common practice (research and design for prevention, compensation, care, work and enjoyment), and (iii) a collaboration as is shown in the two focal points in journals and conferences organized by IEEE and ISG.
4 pertained to Housing \& Daily Living, and the remaining 3 concerned Health \& Self-Esteem. In each of the life domains, (Social) psychology and Medicine \& Rehabilitation took the lead. The most active technology discipline is ICT, contributions of which ranged from 8 to $12 \%$ of the publications in each life domain.
Table 1. Cited gerontechnology contributions in mostly used journals and conference books ( at least 10 cited contributions/journal or / conference book), sorted by focus on technology or gerontology, according to Google Scholar

\begin{tabular}{|c|c|c|c|}
\hline \multirow{2}{*}{ Publication channel } & \multirow{2}{*}{$\mathbf{n}$} & \multicolumn{2}{|c|}{$\%$} \\
\hline & & Technology & Gerontology \\
\hline Journals & & & \\
\hline IEEE Engineering in Medicine and Biology Magazine & 11 & 25 & 75 \\
\hline Gerontechnology (ISG) & 80 & 40 & 60 \\
\hline Conferences & & & \\
\hline Gerontechnology World Conferences (ISG) & 84 & 20 & 80 \\
\hline IEEE conferences and workshops & 44 & 32 & 68 \\
\hline Meetings Association for Computing Machinery (ACM) & 18 & 28 & 72 \\
\hline Meetings Human Factors and Ergonomics Society (HFES) & 10 & 20 & 80 \\
\hline
\end{tabular}




\section{Gerontechnology engineer}

However, the technology focus is on ICT applications. Other engineering domains, such as architecture and construction, business management and material sciences are still hardly touched by gerontechnology. This also led to a partial coverage of life domains with little interest in work, leisure, or mobility. There is room for gerontechnology engineers to cover more ground in the future.

\section{Acknowledgement}

The research was financially supported by UCB (University Centre for Building Production). We are grateful to professor emer. dr Herman Bou$\mathrm{ma}$ for inspiring discussions.

\section{References}

1. Fozard JL My road to and through gerontechnology: An autobiography. Gerontechnology 2010;9(3):368-379; doi:10.4017/ gt.2010.09.03.002.00

2. Rogers WA, Stronge AJ, Fisk AD. Technology and aging. Reviews of Human Factors and Ergonomics 2005;1(1):130-171; doi:10.1518/155723405783703028

3. Graafmans JAM, Brouwers T. Gerontechnology, the modeling of normal aging. Proceedings $33^{\text {rd }}$ Human Factors and Ergonomics Society Annual Meeting. Denver; 1989, pp 187-190

4. Bouma H, Graafmans JAM, editors. Gerontechnology. Studies in Health Technology and Informatics. Volume 3. Amsterdam: IOS Press; 1992

5. Bronswijk JEMH van, Bouma $\mathrm{H}$, Fozard JL, Kearns WD, Davison GC, Tuan P-C. Defining gerontechnology for R\&D purposes. Gerontechnology 2009;8(1):3-10; doi:10.4017/gt.2009.08.01.002.00

6. Graafmans J, Taipale V, Charness N. Gerontechnology: A sustainable investment in the future. Studies in health Technology and Informatics. Volume 48. Amsterdam: IOS Press; 1998

7. Pieper R, Vaarama M, Fozard JL. Gerontechnology: Technology and Aging - Starting into the Third Millennium. Aachen: Shaker; 2002
8. Charness N, Czaja S, Fisk AD, Rogers WA, editors. Gerontechnology 2002: Creative use of technology for better aging. Gerontechnology 2002;2(1):1-155; doi:10.4017/ gt.2002.02.01.000.00

9. Sagawa K, Kurakata K, Yamaba K, Nagamachi M. Conference issue Nagoya, May 25-27, 2o05. Gerontechnology 2005;3(4):185-259; doi:10.4017/ gt.2005.03.04.000.00

10. Bouma H, Dario P, Micera S, Fozard JL, Sagawa K. Conference issue Pisa, June 4-6, 2008. Gerontechnology 7(2):63-252, i-x; doi:10.4017/gt.2008.07.02.000.00

11. Sixsmith A, Goodman G, editors. Abstracts of the $7^{\text {th }}$ World Conference. Gerontechnology 2010;9(2):i-xii, 63-347, xiii-xxiv; doi:10.4017/gt.2010.09.02.000.00

12. Bronswijk JEMH van, Maas GJ, Gassel FJM van. ISG*ISARC2012 well underway. Gerontechnology 2011;10(2):122123;doi:10.4017/gt.2011.10.2.011.00

13. Hsu Y-L. ISG-Sinophone Chapter. Gerontechnology 2011;10(3):186; doi:10.4017/ gt.2011.10.3.008.00

14. Google search with keyword "gerontechnology"; retrieved December 6, 2011

15. Harzing A-WK, Wal R van der. Google Scholar as a new source for citation analysis. Ethics in Science and Environmental Politics 2008;8(1):61-73; doi:10.3354/ esep00076

16. Harzing A-WK. Publish or Perish, version 3.0.1813; 2010; www.harzing.com/pop. htm; retrieved October 14, 2010

17. Wenger E. Communities of practice: learning, meaning and identity. Cambridge: Cambridge University Press; 1998 